\title{
Um sujeito no mercado das pílulas*1
}

\author{
Vera Lopes Besset*2
}

O consumo iguala todos como semelhantes, a partir de soluções para-todos, desconsiderando a particularidade da subjetividade. $O$ fibromiálgico recusa o tratamento universal ofertado pela ciência, seu tratamento deve respeitar a lógica do caso a caso. A discussão proposta se ancora em dados clínicos para pensar a especificidade de uma subjetividade, para além da patologia, forjada a partir de uma ordem de ferro, em tempos de declínio do poder norteador do amor ao pai.

Palavras-chave: Fibromialgia, consumo, subjetividade, clínica psicanalítica

*1 Apresentado em primeira versão no Colóquio Internacional sobre Metapsicologia da Perversão. Usos Sociais da Perversão. No Simpósio "Consumidor: perversão e discurso capitalista". Organizado por Universidade Católica de Pernambuco - Unicap (Recife, PE, Br) e Université Catholique de l'Ouest (Angers, France) e realizado na Unicap em agosto de 2013.

*2 Universidade Federal do Rio de Janeiro - UFRJ (Rio de Janeiro, RJ, Br). 


\section{Introdução}

O consumo iguala todos como semelhantes, a partir de soluções prêt-à-porter e para-todos. Frente ao mal-estar na cultura, os objetos prometem a felicidade. Como assinala a obra freudiana (Freud, 1930/1986), alcançá-la perenemente é impossível, seu usufruto é contingente. Pode-se lançar mão de distrações e satisfações substitutas ou substâncias embriagadoras. Os medicamentos, como os psicotrópicos, mas igualmente substâncias contra alguns males, como os da dor crônica, podem ser incluídos entre os objetos de consumo propriamente dito.

Nesse contexto, uma nova categoria de doentes vem desacomodar o já atestado e sabido. Para eles, a solução universal não se aplica e o tratamento deve ser pensado caso a caso. A fibromialgia reivindica direito de cidadania, reconhecimento e respeito, ${ }^{1}$ convocando-nos ao trabalho. Trata-se de pacientes que nem sempre encontram acolhimento para sua queixa, em particular quando os exames não identificam uma causa orgânica (Besset, Gaspard, Doucet, Veras, Cohen, 2010). Sônia, com diagnóstico de fibromialgia, relata: "Minha cardiologista disse que eu invento as doenças em mim".

$\mathrm{Na}$ clínica psicanalítica, as dores da fibromialgia podem se apresentar como um sintoma silencioso, um sintoma mudo (Miller, 1997). $\mathrm{Na}$ realidade, são sofrimentos que não podem, do ponto de vista da psicanálise, ser nomeados sintomas. Chegam ao analista como queixa e se apresentam como transtorno. A demanda, nesses casos, é de alívio. Falta a eles um endereçamento ao Outro, não portam um sentido nem se oferecem à decifração. "Em realidade são os sintomas

${ }^{1}$ Em março de 2007, a partir da demanda de um cidadão no sentido do reconhecimento da fibromialgia, o Jornal do Senado da França publica a resposta do Ministère de la Santé et des Solidarités, com o título Reconnaissance de la fibromyalgie <http://www.senat.fr/questions/ base/2007/qSEQ070326683.html>. 
mudos, que antigamente não eram levados às práticas do dizer, isso tem a ver com o estado da cultura" (Miller, 1997, p. 9). Ao invés de interpelarem os sujeitos, apresentando-se como enigmas e convidando à construção de um saber, funcionam como respostas ao vazio identificatório que caracteriza aqueles que os portam.

\section{Da dor sem sentido ao sentido da dor}

A dor coloca questões cruciais sobre o corpo e a regulação das pulsões e, em alguns casos, as experiências de dor contrariam a suposição do sujeito (neurótico) de possuir um corpo (Abelhauser, 2010). Quando é questão de psicose, a clínica demonstra que as dores crônicas podem servir de recurso para constituir um corpo (Ebtinger, 2007).

Sônia tem diagnóstico de fibromialgia e frequenta o serviço de dores crônicas atrelado a nossa pesquisa-intervenção (Besset, 2011). Tem atendimento médico, encontra-se semanalmente com uma psicóloga e participa de um Grupo de Fala, reunião mensal coordenada por uma psicóloga e por um médico. Recentemente, ao relatar ter vivido 14 dias sem a dor, o que percebeu pelo número de remédios que deixara de tomar, acrescenta: "As coisas que a Dra $\mathrm{X}$ fala ficam... vou embora pensando nelas. Devo dizer que doem. Sabem por que doem? Porque ficam na gente como alfinetes...". Sônia parece ter substituído, mesmo que em um intervalo, a dor no corpo por algo que a implica em seu ser de gozo. Algo que remete ao feminino pelo viés da maternidade e que a interroga como questão, incômoda como um alfinete. Nesse caso, a dor corporal indica seu caráter de mensagem a ser decifrada. Revela-se um sintoma freudiano: tem relação com a história do sujeito, tem um sentido e se oferece à decifração (Zanotti, Abelhauser, Gaspard, Besset, 2013).

No caso de Sônia, após um trabalho preliminar, primeiro tempo do tratamento, sob transferência, a queixa pôde se desdobrar em sintoma analítico. Entretanto, em alguns casos, a dor não se apresenta como sintoma, mostrando-se impermeável à interpretação. Por vezes, tal como os sintomas obsessivos, remetem-nos a um sentido de satisfação pulsional. Em outros, a dor vem, por assim dizer, fazer um corpo para o falasser que não dispõe de uma imagem corporal que sustente a ilusão de ter um corpo. É o caso de Patrick, relatado por Ebtinger (2007).

Patrick, vendedor e pai de família, levava sua vida sem problemas até o momento em que sofre um acidente de carro. Com ferimentos relativamente leves, desde então sofre de dores nas costas que o impedem de retornar à sua vida profissional e restringem consideravelmente seus afazeres cotidianos. Ao investigar a cronologia e circunstâncias da aparição da dor na vida desse paciente, Ebtinger encontra indicações a respeito de sua instalação. No acidente de carro 
há uma primeira batida e, quando Patrick se volta para entender o que acontecera, um terceiro veículo bate violentamente em seu carro. Ele perde a consciência por instantes e se crê morto, tendo o sentimento de que tudo que vê é irreal. Imediatamente, nada sentiu. Somente no momento seguinte as dores surgiram nos locais do corpo que sofreram um choque (não sofrera ferimentos, apenas contusões). Percebeu que estava vivo somente no instante em que sentiu a dor. No entanto, a impressão de irrealidade permaneceu.

A experiência de sentir-se morto pôs em questão o modo de relação de Patrick com seu corpo. Ebtinger assinala: "é a sensação de seu corpo que funda sua realidade, e não a imagem que ele tem dele" (p. 150). Considerando a função de enlace da dor, no caso de Patrick, Ebtinger indica à equipe uma estratégia de tratamento visando apenas um alívio e não a supressão da dor. Enlaçamento, eis o que está em questão para cada falasser, para enodar os três registros e fazer face ao Real do gozo.

\section{Novos tempos, novos sujeitos, novas patologias?}

O contexto no qual se insere a clínica psicanalítica difere daquele de seus primórdios, no final do século XIX. Laurent e Miller caracterizam a época em que vivemos como a do 'Outro que não existe' (Miller, 2005), na qual se observa o declínio da função paterna, da autoridade e a queda dos ideais. E se hoje o mal-estar assinalado por Freud (1930/1986) no final da década de 1920 permanece, as soluções à disposição do falasser se multiplicam.

$\mathrm{O}$ advento do discurso do capitalista produz modificações no estatuto do sujeito a partir das transformações na cultura, ordenada por esse discurso, avesso às coisas do amor e à particularidade do desejo. Discurso que não é propriamente um, posto que se produz por uma mutação do discurso do mestre e não por uma rotação de seus termos (Lacan, 1978, p. 40):

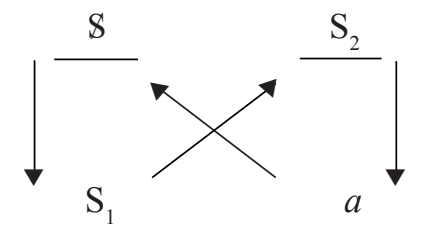

Em seu Seminário sobre a ética da psicanálise, pronunciado no final da década de 1960 (1959-1960/1986), Lacan sublinha a função dos bens produzidos pelo capitalismo: colocar-se à disposição da utilidade. Explicita que "em prol da utilidade, 
tampona-se o que falta com esses pequenos objetos, substituíveis a todo tempo" (p. 280). Mais recentemente, Bauman (2007) afirma que do ponto de vista da utilidade e em prol da descartabilidade o capitalismo permite situar "o valor da novidade acima do valor da permanência" (p. 108).

Nessa configuração dos laços, a ideia de que há um objeto que pode preencher sua falta faz com que o sujeito perca de vista a impossibilidade, presente no discurso do mestre. Sendo assim, sai de cena a castração e a relação entre o sujeito e o objeto não passa pela fantasia: "O sujeito do inconsciente em algum lugar sabe que é impossível apropriar-se do objeto e por isso precisa da fantasia" (Dafunchio, 2008, p. 46). A incompletude se apresenta a esse sujeito não pela via da falta a ser, que o regularia a partir do ideal, como solução, mas apresenta-se como falta-de-gozo, na perspectiva do mais-gozar apontado pelos objetos. Esse sujeito é o consumidor.

Ao contrário do gozo singular, próprio ao Um, temos a promessa de um gozo igual para todos e sem limites, universal. Cada um busca, como pode, o limite, ou o véu para lidar com o real do gozo. Não há um Outro que, se existisse, garantiria a relação sexual. Essa fórmula de Lacan (2005) (Encore) indica algo que não funciona nos seres falantes, seres de linguagem, algo que se manifesta no campo da sexualidade. Algo que Lacan nomeia troumatisme e que, para Freud, era um excedente de sexualidade (Miller, 1988).

Uma vez que a relação sexual não existe (Lacan, 1975), que o pai do Nome-do-Pai não consegue garantir a relação entre significante e significado, a conclusão é que não existe nó borromeano de três (Lacan, Seminário 23, 2005). Há sempre lapso, falha do nó, por isso o déficit é generalizado. É preciso um $4^{\circ}$ nó para que o sujeito se proteja do real e sustente junto real, simbólico e imaginário. Algo que funcionaria como suplência: como um Nome-do-Pai, que Lacan nomeou Sinthome (Seminário 23, 2005).

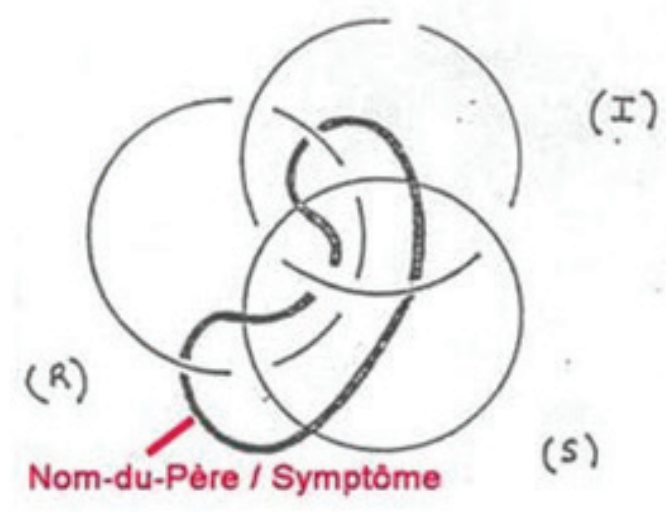




\section{ARTIGOS}

Ou algo que, funcionando como nomeação, venha reforçar uma das rodelas de barbante (Seminário R.S.I.): a Inibição (I), o Imaginário, o Sintoma (S), o Simbólico e a Angústia (A), o Real.

Figura: nó de três com reforço do simbólico (sintoma)

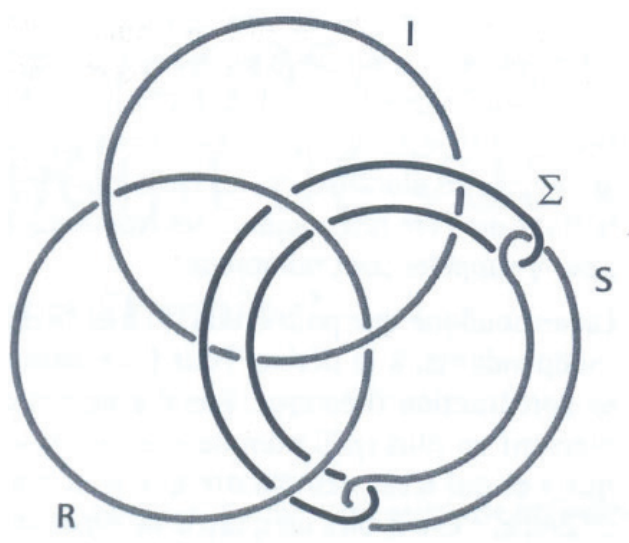

Trata-se de outro tempo, no qual já não vigora o não do pai, da interdição que funda a lei e está na origem do desejo. Assim, sem recursos para construir um sintoma que faça laço com o Outro, o sujeito apresenta-se muitas vezes desnorteado e à deriva.

No Seminário Les non-dupes errent (1974/2014), Lacan assinala uma característica daquele momento histórico: a perda de dimensão do amor, em que o nome do pai é substituído pela função de nomear para (nommer à). Trata-se não mais do não em nome do pai, mas de um não que depende somente da voz da mãe e de sua vontade, de interditar algo aqui e ali. A interdição, então, incide sobre pequenas coisas e somente quando se tem sorte de a mãe querer assim. A mãe se basta sozinha, pode designar o projeto, traçá-lo, indicar o caminho: "Ser nomeado para algo, eis o que se destaca em uma ordem que efetivamente se substitui ao Nome-do-Pai". Aí o social ganha relevância, relevância de nó, porque ele tem o poder de "nomear para". Desse modo, restitui uma ordem que, afinal, afirma Lacan, "é uma ordem de ferro".

É uma nomeação que permite um encadeamento. No entanto, é um encadeamento muito rígido, mais rígido do que se conhece habitualmente na neurose. Então, as formas clínicas mudam. Nesse outro tipo de nomeação, "o sujeito anda 
direitinho", cumpre um mandato e, por vezes, se comporta como um robô, obedecendo às normas sociais (Dafunchio, 2008, p. 48). Sujeitos que, como Patrick, não dispõem do NP para nomear e, a partir disso, localizar o gozo no corpo, recortando-o.

Sem o Nome-do-Pai, sublinha Miller (1994), não há, propriamente falando, o corpo; há o corporal, a carne, a matéria, a imagem. Há acontecimentos de corpo, acontecimentos que destroem o corpo. Sem o Nome-do-Pai, é um sem-o-corpo. Nesse contexto, concordamos com Focchi (2013) que sublinha o apagamento dos limites entre neurose e psicose no último ensino de Lacan. Sendo assim, "La folie entendu comme impossible d'affronter la sexualité au moyen du savoir, du logos, de la raison, concerne tous les êtres parlants sans distinction catégorielle".

\section{Um saber fazer possível}

Neste século, no qual a ideia do homem como um complexo circuito de neurônios vivificado por substâncias ganha força e prestígio, a psicanálise reafirma seu dever ético de manter aberto o debate sobre o falasser e aquilo que o afeta. Face ao predomínio do discurso do capitalista e do prestígio do saber da ciência, "L'analyste, pour sa part, loge un Autre savoir, le savoir de l'inconscient, et dans un Autre lieu, le lieu de l'Autre qui n'existe que par le transfert", como afirma Bassols (2013).

Nos casos em que a certeza comparece no lugar do saber, é possível acompanhar o sujeito na construção de um saber fazer com o real sem lei (Miller, 2012, p. 92). Na abordagem de casos de dor crônica, é útil lembrar que o diagnóstico médico pode funcionar como nome para localizar o falasser na relação com o Outro (Besset \& Espinoza, 2012). É assim com a fibromialgia, a exemplo do que se observa com os nomes oferecidos pela psiquiatria biológica: fobia social, transtorno bipolar, déficit de atenção (TDHA), entre outros.

Nesse contexto, os fibromiálgicos indicam que, de algum modo, não se deixam iludir com a promessa das pílulas, mas demandam sem cessar um Outro. Em alguns casos, a persistência da dor pode indicar algo estruturalmente necessário a um falasser. Assim, a abordagem desses casos se orienta pela função que a dor crônica pode ter no enlaçamento RSI. Por isso, a relevância de investigar a possível função da dor no enlaçamento dos registros, de modo a respeitar seu lugar e conduzir o tratamento, apoiando-se na transferência, nome freudiano do amor.

\section{Referências}

Abelhauser, A. (2010). La douleur: parole — ou fonction — du corps? Conferência (inédita). 


\section{ARTIGOS}

III Jornada de Estudos do CLINP (Núcleo de Pesquisas Clínica Psicanalítica)-UFRJ/CNPq. 22.10.2010. Instituto de Psicologia/UFRJ. Rio de Janeiro, Brasil.

Bassols, M. (2013). Dans la psychanalyse, il n'y a pas de savoir dans le réel. Textes d'orientation. IXe Congrès de l'AMP. Recuperado em 10 abr.2014 de <http://www.congresamp2014.com>.

Bauman, Z. (2007). Tempos líquidos. Rio de Janeiro: Jorge Zahar.

Besset, V.L. (2011). Corpo e dor: o desafio das dores crônicas-Módulo I. Projeto de PesquisaIntervenção. Circulação restrita.

Besset, V.L., Gaspard, J., Doucet, C. \& Veras, M. A. S., Cohen, R. H. (2010). Um nome para a dor: fibromialgia. Revista Mal-Estar e Subjetividade, 10, 1245-1269.

Besset, V.L. \& Espinoza, M.P.V. (2012). Dora hipermoderna: ainda a histeria? In J. Vilhena \& J. Novaes (Orgs). Corpo para que te quero? Usos, abusos e desusos (pp. 303-313). Rio de Janeiro: PUC-Rio: Appris.

Dafunchio, N.S. (2008). Confines de las psicoses. Buenos Aires: Del Bucle.

Ebtinger, P. (2007). Douleur dans la réalité subjective. Mental. Revue Internationale de Santé Mentale et Psychanalyse Appliquée, 19, 148-151.

Focchi, M. (2013). La cause réelle est la cause non nécessaire. Textes d'orientation. IXe Congrès de l'AMP. Recuperado em 10 abr.2014 de <http://www.congresamp2014.com>.

Freud, S. (1986). El malestar en la cultura. In Obras Completas (Vol. XXI, pp. 57-140). Buenos Aires: Amorrortu. (Trabalho original publicado em 1930).

Lacan, J. Les non dupes errent. 19 Mars 1974. Recuperado em 10 abr.2014 de <http://espace.freud. pagesperso-orange.fr/topos/psycha/psysem/nondup/nondup10.htm>.

Lacan, J. (1975). Le Séminaire. Livre XX. Encore. Paris: Seuil.

Lacan, J. (1978). Discours de Jacques Lacan à l'Université du Milan le 12 mai 1972. In Lacan in Italia. En Italie Lacan (pp. 32-55). Milan: La Salamandra.

Lacan, J. (1986). Le Séminaire. Livre VII. L'éthique de la psychanalyse. Paris: Seuil.

Lacan, J. (2005). Le Séminaire. Livre XXIII. Le sinthome. Paris: Seuil.

Miller, J.-A. Cause et consentement. Curso de Orientação Lacaniana. Departamento de Psicanálise. Université Paris VIII. Aula de 13 de janeiro de 1988.

cMiller, J.-A. (1994). «L’orientation lacanienne. Pièces Détachées». Curso. Departamento de Psicanálise. Universidade Paris VIII, lição de 15 de dezembro de 1994, inédito.

Miller, J.-A. (1997). O sintoma e o cometa. Opção Lacaniana, n. 19, p. 5-13.

Miller, J.-A. (2005). El Otro que no existe y sus comites de ética. Buenos Aires: Paidós.

Miller, J.-A. (2012). Le réel au XXIe siècle. Présentation du thème du IXe Congrès de l'AMP. La Cause du Désir, 82.

Zanotti, S.V., Abelhauser, A., Gaspard, J-L. \&, Besset, V.L. (2013, setembro). Aux limites de l'hystérie, la douleur chronique. Revista Latinoamericana de Psicopatologia Fundamental, 16(3), 425-437. 


\section{Resumos}

(A subject at the pill market)

Consumption treats everyone in the same way and offers solutions for all regardless of individuality. But fibromyalgia patients refuse this kind of treatment offered by science. Their treatment requires a study of each case. This paper, based on clinical data, brings up the question of subjectivity and its idiosyncrasies, beyond pathology, in a context of iron in times of decay of the guiding power of the father's love.

Key words: Fibromyalgia, consumption, subjectivity, psychoanalytic clinic

(Un sujet au marché des pilules)

La consommation nous rend tous égaux, tous semblables, étant donné ses solutions pour tous qui ne prennent pas en compte la particularité de la subjectivité. La fibromyalgie refuse tout traitement universel offert par la science, son traitement suit la logique du cas particulier. La discussion proposée ici est basée sur des données cliniques et porte sur la spécificité d'une subjectivité qui va au-delà de la pathologie et qui est construite à partir d'un ordre de fer, en ces temps de déclin du pouvoir d'orientation de l'amour au père.

624 Mots clés: Fibromyalgie, consommation, subjectivité, clinique psychanalytique

(Un sujeto en el mercado de las pastillas)

El consumo iguala a todos como semejantes a partir de soluciones para todo el mundo, sin tener en cuenta la particularidad de la subjetividad. Los pacientes con fibromialgia rechazan el tratamiento universal que la ciencia les ofrece, su tratamiento debe respetar la lógica del caso por caso. La discusión que se propone se basa en datos clínicos para pensar la especificidad de una subjetividad, más allá de la patología, forjada a partir de un orden férro en tiempos de decadencia del poder orientador del amor al padre.

Palabras clave: Fibromialgia, consumo, subjetividad, clinica psicoanalítica

\section{(Ein Subjekt im Pillenmarkt)}

Für den Konsum sind alle gleich und er bietet einheitliche Lösungen für alle an, ungeachtet der individuellen Eigenart der Subjektivität. Ein Patient mit Fibromyalgie lehnt die von der Wissenschaft angebotene Standardbehandlung ab, seine Behandlung muss die Fall-für-Fall-Logik berücksichtigen. Die vorgeschlagene Diskussion gründet auf klinischen Daten, um sich mit der Spezifität der Subjektivität über die Pathologie hinaus zu beschäftigen. Eine Pathologie, die aufgrund einer eisernen Anordnung, in einer Zeit des Verfalls der Orientierungsmacht der Liebe zum Vater, geschmiedet wurde.

Schlüsselwörter: Fibromyalgie, Konsum, Subjektivität, psychoanalytische Klinik 


\section{ARTIGOS}

Citação/Citation: Besset, V.L. (2014, setembro). Um sujeito no mercado das pílulas. Revista Latinoamericana de Psicopatologia Fundamental, 17(3-Suppl.), 616-625.

Editor do artigo/Editor: Prof. Dr. Manoel Tosta Berlinck

Recebido/Received: 15.3.2014/3.15.2014 Aceito/Accepted: 10.4.2014 / 4.10.2014

Copyright: (C) 2009 Associação Universitária de Pesquisa em Psicopatologia Fundamental/ University Association for Research in Fundamental Psychopathology. Este é um artigo de livre acesso, que permite uso irrestrito, distribuição e reprodução em qualquer meio, desde que o autor e a fonte sejam citados / This is an open-access article, which permits unrestricted use, distribution, and reproduction in any medium, provided the original author and source are credited.

Financiamento/Funding: Pesquisa financiada pela Fundação de Amparo à Pesquisa do Estado do Rio de Janeiro - Faperj e do Conselho Nacional de Desenvolvimento Científico e Tecnológico - CNPq / The research was funded by the Fundação de Amparo à Pesquisa do Estado do Rio de Janeiro - Faperj and Conselho Nacional de Desenvolvimento Científico e Tecnológico - CNPq.

Conflito de interesses/Conflict of interest: A autora declara que não há conflito de interesses / The author has no conflict of interest to declare.

\section{VERA LOPES BESSET}

Doutora em Psicologia Aplicada (Université Paris V); Programa de Pós-Graduação em Psicologia. Universidade Federal do Rio de Janeiro.

Av. Pasteur, 250. Pavilhão Nilton Campos, Praia Vermelha - Urca

22290-240 Rio de Janeiro, RJ, Br.

e-mail: besset@terra.com.br 